\title{
Various Factors Affecting Short-Term Compliance Rates of CPAP in OSA Patients: in the Age of Insurance Coverage in Korea
}

\author{
Oh Eun Kwon, $\mathrm{MD}, \mathrm{PhD}^{1 *}$, Youngmin $\mathrm{Hah}, \mathrm{MD}, \mathrm{PhD}^{2 *}$, and $\mathrm{Il}$ Hee Hong, $\mathrm{MD}, \mathrm{PhD}^{2}$ \\ ${ }^{1}$ Department of Otorhinolaryngology-Head and Neck Surgery, Kangdong Sacred Heart Hospital, Seoul; and \\ ${ }^{2}$ Seoul Sleep Clinic, Seoul, Korea
}

\begin{abstract}
Background and Objectives: Although many studies have explored the factors affecting compliance with continuous positive airway pressure (CPAP) in patients with obstructive sleep apnea (OSA), the findings remain controversial. This study aimed to analyze CPAP compliance after insurance coverage began in Korea and to investigate what factors influenced CPAP compliance. Materials and Method: The subjects were 1,037 patients who were prescribed a CPAP after polysomnography at the Seoul Sleep Clinic; data were reviewed retrospectively. We classified those that used a CPAP for more than 4 hours per day for $70 \%$ or more days per month as into the good compliance group. We compared the ratio of good compliance by gender, position dependence, rapid eye movement (REM) dependence, telemonitoring of CPAP, pressure modification, and OSA severity.

Results: There were no statistically significant differences in ratio of good compliance group according to gender, position dependence, REM dependence, or disease severity. When using a fixed CPAP (92.2\%) rather than an auto PAP (88.4\%), the ratio of patients in the good compliance group was significantly higher. Non-positioner and fixed CPAP users showed significantly longer average usage time.

Conclusion: In a 3-month short-term follow-up study of CPAP compliance, the telemonitoring group and those using a fixed CPAP showed a higher ratio of good compliance. Average CPAP usage time was longer when using a fixed CPAP and in nonpositioners. As age increased, CPAP usage time was longer, and the average compliance rate tended to increase.
\end{abstract}

KEY WORDS: Obstructive sleep apnea $\cdot$ Continuous positive airway pressure $\cdot$ Compliance $\cdot$ Position-dependent OSA $\cdot$ Age.

\section{INTRODUCTION}

Obstructive sleep apnea (OSA) is one of the relatively common chronic disorders. Sleep fragmentation and hypoxemia caused by frequent wakefulness of the brain can cause daytime sleepiness and decreased cognitive ability, lead to a poor quality of life and impairment to social life, as well as complications leading to cardiovascular disease, so treatment is essential. ${ }^{1-3)}$ Continuous positive airway pressure (CPAP) is one of the main treatment methods for OSA, which has been recognized as a gold standard medical treatment because it can improve excessive daytime sleepiness, improve quality of life, and contribute to the prevention of cardiovascular disease related complications. ${ }^{3-6)}$ CPAP devices have been used for the treatment of OSA for decades since its introduction, but known problems include that it must be used for a lifetime, has a low compliance rate as it causes discomfort in the nose and chest. ${ }^{78)}$ A lot of research has been done on what affects CPAP compliance, but it is still controversial. ${ }^{9)}$

On July 1, 2018, the Korean national health insurance coverage was applied to polysomnography (PSG) and CPAP therapy if the patients meet the criteria of OSA. Before the starting of Korean national health insurance coverage of sleep apnea diagnosis and treatment, the cost of PSG was high and patients have to buy the CPAP device

Received: October 17, 2020 / Revised: November 23, 2020 / Accepted: November 24, 2020

*Oh Eun Kwon and Youngmin Hah contributed equally to this work.

Address for correspondence: II Hee Hong, MD, PhD, Seoul Sleep Clinic, 704 Nonhyun-ro, Gangnam-gu, Seoul 06052, Korea

Tel: +82-2-511-0777, Fax:+82-2-511-1175, E-mail: ilheehong2@gmail.com 
by themselves. When the Korean national health insurance cover the cost of PSG and CPAP therapy, the patient's cost burden was greatly reduced. Therefore, increasing the demand of PSG and CPAP therapy and highlighting its importance, but analyzed data on the prescription status and compliance of CPAP devices is rare in Korea. The purpose of this study was to analyze the current status of CPAP prescriptions after domestic insurance coverage, and to find out which factors influenced the CPAP compliance rate.

\section{MATERIAL AND METHODS}

\section{Subjects}

This study was conducted on patients who were prescribed CPAP after diagnosis of OSA according to the result of PSG over the period of July 1, 2018 to December 31, 2019 at Seoul Sleep Clinic. Of 1,104 total patients, 46 were excluded because their prescription period has not passed until December 31st, and 21 were excluded due to a loss of voluntary 3-month follow-ups, so in total 1037 patients were included. All 1,104 patients were diagnosed OSA by the level I PSG test, and 590 of them additionally underwent the CPAP titration test to determine the optimal pressure. Reading of all PSG results, including the sleep stage and setting of the optimal pressure was performed according to the reading standards set by the American Academy of Sleep Medicine (AASM). According to the number of RDI events, we categorized the severity of OSA into groups: severe; RDI $\geq 30$ events/hr and mild to moderate group; $5 \leq$ and $<30$ events/hr.

CPAP was prescribed when the Apnea Hypopnea Index (AHI) is 15 or higher, or when AHI was 5 or higher and less than 15 with the minimum oxygen saturation being less than $85 \%$ in PSG results. In addition, when AHI was 5 or more and less than 15 with the minimum oxygen saturation being $85 \%$ or more, CPAP was still prescribed when one or more symptoms of insomnia, excessive daytime sleepiness, mood disorder, cognitive function impairment, hypertension, heart disease, or stroke history were present.

This study was approved by the Institutional Review Board of Public Use under Ministry of Health and Welfare prior to its initiation (IRB No. P01-202007-21-031).

\section{Study design}

All patients underwent a one-on-one interview on sleep hygiene, how to use a CPAP device, precautions when us- ing it, and expected effects after use. Subsequently, follow-up observations were performed on the 1-month and 3-month mark, and during the follow-up period interviews and educational sessions were conducted on mask suitability, correct usage of CPAP, and effectiveness of controlling apnea based on the information stored in the devices. All CPAP patients used either the nasal or pillow type mask, and the CPAP devices used were either the Philips' Dream station or ResMed S10 model. The choice of device manufacturer was left to the patient. For the selection of the mask types, all patients had trials at the sleep clinic before using the device. Within 3 months, if the patients had trouble with the mask type, another type of mask was prescribed. We categorized the two groups depends on the telemonitoring of patients. Of the two manufacturers, ResMed had a system to share the situation with patients and encourage use through feedback several times during the compliance period, and Philips did not have such a feedback system at the time of data collection. Therefore, we classified Philips, which has no telemonitoring protocol, into no telemonitoring group (manufacturer A) and ResMed, which has a telemonitoring protocol, into a telemonitoring group (manufacturer B) and conducted research. The telemonitoring was done by the person in charge of the device for 3 months usage of CPAP regularly.

According to Cartwright's classification, we defined a position-dependent OSA (POSA) when the AHI differed by more than $50 \%$ between the supine position and nonsupine position. When AHI differed by more than $50 \%$ between REM sleep and NREM sleep, we defined REM-related OSA. ${ }^{10)}$

Automatic positive airway pressure (APAP) devices were adjusted between a range of 4 to $13 \mathrm{~cm} \mathrm{H}_{2} \mathrm{O}$ according to individual patient conditions. All patients using fixed CPAP underwent an all-night titration test or split-night PSG under the supervision of an experienced expert for determining optimal pressure according to the AASM guidelines. When using a fixed CPAP, the EPR level was set to $1 \mathrm{~cm} \mathrm{H}_{2} \mathrm{O}$.

Based on information stored in the devices during the 3-month study period, patients were divided into two groups evaluated on CPAP compliance rates. Patients were classified into the 'good compliance group' when meeting CPAP usage time conditions of 4 hours or more per night for $70 \%$ of 30 nights ${ }^{11)}$ within the 3-month follow-up period, and otherwise classified as the 'poor compliance group.' 


\section{Statistical analysis}

Categorical variables were compared using the chi-squared test. Parametric grouped data were presented as mean values with their standard deviations (SDs) using the Student t-test, and non-parametric grouped data were compared using the Mann-Whitney U test. For analysis of factors influencing CPAP compliance, we used the binary logistic regression analysis. Statistical significance was set at $\mathrm{p}<0.05$. The statistical analysis of data was performed with the SPSS v 20.0 statistical software (IBM Corp., Armonk, NY, USA).

\section{RESULT}

Out of 1,037 patients, 939 patients $(90.5 \%)$ were in the 'good compliance group' and 98 patients $(9.5 \%)$ were in the 'poor compliance group' at the 3-month follow-up. The mean age of all enrolled patients was $47.36 \pm 12.25$. In good compliance group, the mean age was significantly higher than in poor compliance group (Table $1, \mathrm{p}=0.001$ ). However, there were no significant differences in AHI, RDI and lowest $\mathrm{O} 2$ saturation between two groups. The number of severe OSA patients was 891 (85.9\%) in all enrolled patients, but the proportion of severe OSA group was not different between good and poor compliance group significantly (Table $1, \mathrm{p}=0.17$ ).

\section{Comparison of the ratio of a good compliance group}

\section{Gender}

Eighty-five patients (8.2\%) were female and 952 (91.8\%) were male. The rate of 'good compliance group' was $90.2 \%$ (859 out of 952) in males and $94.1 \%$ (80 out of 85 ) in females, which was higher in females than in males but there was no statistical significance (Table $1, \mathrm{p}=0.33$ ). The average CPAP usage time in 3 months was longer in female than in male, and the average $\mathrm{AHI}_{\mathrm{CPAP}}$ was lower in female than in male, but there was no statistically significant difference (Table $2, \mathrm{p}=0.37$ and $\mathrm{p}=0.18$, respectively).

\section{Position dependence}

There were 486 patients (46.9\%) with position dependence. The ratio of 'good compliance group' and the average $\mathrm{AHI}_{\mathrm{CPAP}}$ were not significantly different between the two groups (Table 1 and $5, p=0.09$ and $p=0.79$ ). The average CPAP usage time in the position-independent group was statistically significant and longer than that of the position-dependent group (Table 2, $\mathrm{p}=0.004$ ).

\section{REM dependence}

The REM-related group included 97 patients (9.4\%) and the non-REM-related group included 940 (90.6\%) patients. The 'good compliance group' rate, the average CPAP usage time, and the average $\mathrm{AHI}_{\mathrm{CPAP}}$ did not show a significant difference between the two groups (Table 1 and 2, $\mathrm{p}=$ $0.09,0.484$, and $\mathrm{p}=0.738$, respectively).

\section{Telemonitoring of CPAP use}

In the 'good compliance group', telemonitoring group was significantly higher compared to no telemonitoring group (Table 3, $\mathrm{p}=0.046$ ). There was no significant difference in the average CPAP usage time between the two

Table 1. Demographics

\begin{tabular}{|c|c|c|c|c|}
\hline & $\begin{array}{c}\text { Total patients } \\
{[n(\%)]}\end{array}$ & $\begin{array}{l}\text { Good compliance } \\
\qquad(n=939)\end{array}$ & $\begin{array}{l}\text { Poor compliance } \\
\qquad(n=98)\end{array}$ & $\mathrm{p}$-value \\
\hline $\begin{array}{l}\text { Compliance after 3-month follow-up } \\
\text { (good:poor) }\end{array}$ & $939(90.5 \%): 98(9.5 \%)$ & & & \\
\hline Age, yr $($ mean $\pm S D)$ & $47.36 \pm 12.25$ & $47.76 \pm 12.34$ & $43.54 \pm 10.64$ & $0.001 *$ \\
\hline Gender (male:female) & $952(91.8 \%): 85(8.2 \%)$ & $859(91.5 \%): 80(8.5 \%)$ & $93(94.9 \%): 5(5.1 \%)$ & 0.33 \\
\hline \multicolumn{5}{|l|}{ Polysomnography data (mean \pm SD) } \\
\hline AHI (events/hr) & $57.62 \pm 28.04$ & $57.59 \pm 28.41$ & $57.93 \pm 24.37$ & 0.71 \\
\hline RDI (events/hr) & $59.88 \pm 26.21$ & $59.80 \pm 26.50$ & $60.66 \pm 24.43$ & 0.61 \\
\hline Lowest O2 saturation (\%) & $78.47 \pm 8.27$ & $78.47 \pm 8.29$ & $78.39 \pm 8.16$ & 0.92 \\
\hline OSA severity (severe:mild-moderate) & $891(85.9 \%): 146(14.1 \%)$ & $802(85.4 \%): 137(14.6 \%)$ & $89(90.8 \%): 9(9.2 \%)$ & 0.17 \\
\hline Position dependence group & $486(46.9 \%)$ & $432(46.0 \%)$ & $54(55.1 \%)$ & 0.09 \\
\hline REM dependence group & $97(9.4 \%)$ & $92(9.8 \%)$ & $5(5.1 \%)$ & 0.14 \\
\hline
\end{tabular}

*: Statistically significant. AHI: apnea-hypopnea index, RDI: respiratory disturbance index, OSA: obstructive sleep apnea, O2: Oxygen, REM: rapid eye movement 
groups, but the average $\mathrm{AHI}_{\mathrm{CPAP}}$ was $3.13 \pm 2.20$ in the no telemonitoring group and $1.59 \pm 1.31$ in the telemonitoring group. As seen in Table 4, when we compared the characteristics of patients depending on the telemonitoring of CPAP use, there were no differences between two groups.

Type of pressure modification

In good compliance group, the number of patients using APAP was 395 (42.1\%) and 544 (57.9\%) patients were used fixed CPAP. However, in poor compliance group, the proportion of APAP was $53.1 \%$ and that of fixed CPAP was $46.9 \%$, which meant the proportion of fixed CPAP user was significantly higher in the good compliance group than in the poor compliance group (Table 3, $\mathrm{p}=0.042$ ). In Table 4, we compared the characteristics of enrolled patients according to the pressure types (auto vs. fixed). In patients using APAP, the proportions of position dependence and REM dependence group were higher than in the patients using fixed CPAP $(p<0.001$ and $p=0.003)$, and the proportion of severe OSA group was significantly higher in the patients group using fixed CPAP $(\mathrm{p}<0.001)$.

\section{OSA severity}

Among the enrolled patients, 891 patients $(85.9 \%)$ were severe OSA. Comparing the mild-moderate OSA group to the severe OSA group, there was a tendency for the 'good compliance group' rate to decrease the more severe OSA symptoms the patient had, but there was no statistically sig-

Table 2. Comparison of the difference in the average usage time and AHI with CPAP according to various factors

\begin{tabular}{|c|c|c|c|c|}
\hline & Average usage time (minute) & p-value & $\mathrm{AHI}_{\mathrm{CPAP}^{\dagger}}{ }^{\dagger}$ (event/hr) & $\mathrm{p}$-value \\
\hline Gender & & 0.37 & & 0.18 \\
\hline Male & $335.95 \pm 74.57$ & & $2.60 \pm 2.06$ & \\
\hline Female & $344.69 \pm 86.79$ & & $2.30 \pm 2.01$ & \\
\hline Position-dependence & & $0.004^{*}$ & & 0.79 \\
\hline Yes & $329.46 \pm 78.77$ & & $2.56 \pm 2.17$ & \\
\hline No & $343.03 \pm 72.25$ & & $2.59 \pm 1.96$ & \\
\hline REM-dependence & & 0.484 & & 0.738 \\
\hline Yes & $332.37 \pm 61.76$ & & $2.64 \pm 2.15$ & \\
\hline No & $337.11 \pm 76.94$ & & $2.57 \pm 2.05$ & \\
\hline CPAP manufacturer & & 0.054 & & $<0.001^{*}$ \\
\hline A & $340.07 \pm 75.32$ & & $3.13 \pm 2.20$ & \\
\hline B & $330.64 \pm 75.94$ & & $1.59 \pm 1.31$ & \\
\hline Pressure type & & $0.025^{*}$ & & $0.003^{*}$ \\
\hline Auto & $330.77 \pm 73.86$ & & $2.80 \pm 2.25$ & \\
\hline Fixed & $341.36 \pm 76.69$ & & $2.41 \pm 1.89$ & \\
\hline OSA severity & & 0.80 & & $0.04^{*}$ \\
\hline Severe & $336.46 \pm 76.87$ & & $2.63 \pm 2.11$ & \\
\hline Mild-moderate & $337.97 \pm 67.88$ & & $2.26 \pm 1.68$ & \\
\hline
\end{tabular}

*: Statistically significant, $\dagger$ : AHI CPAP, apnea-hypopnea index with CPAP device. AHI: apnea-hypopnea index, CPAP: continuous positive airway pressure, CPAP manufacturer A: No telemonitoring, CPAP manufacturer B: telemonitoring (+), OSA: obstructive sleep apnea, REM: rapid eye movement

Table 3. Comparison of CPAP usage data of good compliance ${ }^{\dagger}$ and poor compliance groups for 3 months

\begin{tabular}{lcccc}
\hline & $\begin{array}{c}\text { Total patients } \\
{[n(\%)]}\end{array}$ & $\begin{array}{c}\text { Good compliance } \\
(\mathrm{n}=939)\end{array}$ & $\begin{array}{c}\text { Poor compliance } \\
(\mathrm{n}=98)\end{array}$ & p-value \\
\hline CPAP manufacturer $(\mathrm{A}: \mathrm{B})$ & $663(63.9 \%): 374(36.1 \%)$ & $591(62.9 \%): 348(37.1 \%)$ & $72(73.5 \%): 26(26.5 \%)$ & $0.046^{*}$ \\
Pressure type (auto:fixed) & $447(43.1 \%): 590(56.9 \%)$ & $395(42.1 \%): 544(57.9 \%)$ & $52(53.1 \%): 46(46.9 \%)$ & $0.042^{*}$ \\
Average usage time, min (mean \pm SD) & $336.67 \pm 75.64$ & $349.89 \pm 60.66$ & $210.03 \pm 87.34$ & $<0.001^{*}$ \\
$\begin{array}{l}\text { Average usage time } \geq 4 \text { hours, } \\
\% \text { time (mean } \pm \text { SD) }\end{array}$ & $81.87 \pm 33.83$ & $86.63 \pm 31.25$ & $36.26 \pm 21.29$ & $<0.001^{*}$ \\
AHI CPAP, event/h (mean \pm SD) & $2.58 \pm 2.06$ & $2.47 \pm 1.92$ & $3.54 \pm 2.95<$ & $<0.001^{*}$ \\
\hline
\end{tabular}

*: Statistically significant, $\dagger$ : Good compliance: patients of using CPAP was more than 4 hours per day and $70 \%$ or more per month. CPAP: continuous positive airway pressure, CPAP manufacturer A: No telemonitoring, CPAP manufacturer B: telemonitoring (+),

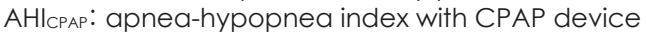


Table 4. Comparisons of various factors depends on the telemonitoring of CPAP manufactures and pressure type (auto vs. fixed)

\begin{tabular}{|c|c|c|c|c|c|c|}
\hline & \multicolumn{2}{|c|}{ CPAP manufacturer } & \multirow{2}{*}{ p-value } & \multicolumn{2}{|c|}{ Pressure type } & \multirow{2}{*}{ p-value } \\
\hline & A & B & & Auto & Fixed & \\
\hline Gender (male:female) & $\begin{array}{c}606 \text { (91.4\%): } \\
57(8.6 \%)\end{array}$ & $\begin{array}{c}346(92.5 \%): \\
28(7.5 \%)\end{array}$ & 0.55 & $\begin{array}{c}404(90.4 \%): \\
43(9.6 \%)\end{array}$ & $\begin{array}{c}548(92.9 \%): \\
42(7.1 \%)\end{array}$ & 0.17 \\
\hline Position dependence group & $324(48.9 \%)$ & $162(43.3 \%)$ & 0.92 & $244(54.6 \%)$ & $242(41.0 \%)$ & $<0.001^{*}$ \\
\hline REM dependence group & $64(9.7 \%)$ & $33(8.8 \%)$ & 0.74 & $56(12.5 \%)$ & $41(6.9 \%)$ & $0.003^{*}$ \\
\hline Severe OSA group & $568(85.7 \%)$ & $323(86.4 \%)$ & 0.78 & $361(80.8 \%)$ & $530(89.8 \%)$ & $<0.001^{*}$ \\
\hline CPAP manufacturer & - & - & ns & $\begin{array}{c}\text { 293(65.5\%): } \\
\text { 154(34.5\%) }\end{array}$ & $\begin{array}{l}370(62.7 \%): \\
220(37.3 \%)\end{array}$ & 0.36 \\
\hline Pressure type & $\begin{array}{c}293(44.2 \%): \\
370(55.8 \%)\end{array}$ & $\begin{array}{l}\text { 154(41.2\%): } \\
220(58.8 \%)\end{array}$ & 0.36 & - & - & ns \\
\hline
\end{tabular}

*: Statistically significant. AHI: apnea-hypopnea index, CPAP: continuous positive airway pressure, CPAP manufacturer A: No telemonitoring, CPAP manufacturer B: telemonitoring (+), OSA: obstructive sleep apnea, REM: rapid eye movement, ns: non specific

nificant difference (Table $1, \mathrm{p}=0.17)$.

\section{Factors influencing the compliance of CPAP use}

According to the result of above, age, telemonitoring of CPAP use and pressure type showed significant differences between good and poor compliance groups. Of the factors we believe will affect the two groups, only the age and telemonitoring of CPAP use have shown to affect compliance (Table 5). According to the results, as the age increasing, the good compliance rate increased [Odds ratio $(\mathrm{OR})=$ $1.10, \mathrm{p}<0.001]$. Also, in case of telemonitoring group, the relative ratio of good compliance group was increased $(\mathrm{OR}=1.72, \mathrm{p}=0.024)$.

\section{DISCUSSION}

This study is that analyzing the characteristics of the 'good CPAP compliance group' patients who were given CPAP prescriptions over the 1 year and 6 months period after beginning the domestic insurance coverage of PAP therapy in Korea. Our study investigated the factors affecting CPAP compliance rate on 3-month follow-up, which is meaningful because it is a condition of continuing CPAP health insurance coverage in Korea.

There was no significant difference in the CPAP compliance rate by gender (Table 1). Previous studies have shown various results for CPAP compliance by gender. ${ }^{3) 12}$ In this study, there was no statistically significant difference, but the average CPAP usage time in women was longer than men (Table 2). Previous study conducted with 4,000 people in Australia reported that the average CPAP usage time in men was significantly longer than in women. ${ }^{12)}$ Another study reported that age and gender were independent of CPAP
Table 5. Logistic regression analysis of various factors (Reference: Poor compliance group)

\begin{tabular}{lcc}
\multicolumn{1}{c}{ Factors } & Odds ratio $(95 \% \mathrm{Cl})$ & p-value \\
\hline $\begin{array}{l}\text { Age } \\
\text { Telemonitoring }\end{array}$ & $1.10(1.09-1.15)$ & $<0.001^{*}$ \\
$\quad$ None & 1 & $0.024^{*}$ \\
Yes & $1.72(1.07-2.75)$ & \\
\hline
\end{tabular}

*: Statistically significant

compliance. ${ }^{4)}$ As such, the results of CPAP compliance according to gender varied for each study, and even if there are differences in CPAP compliance rates according to gender, it needs to be comprehensively judged by considering other variables.

In this study, the proportion of patients with position-dependence was $46.9 \%$ (Table 1). In a previous study, it varied from $21 \%$ to $49.3 \%$ according to the classification method but showed similar results to ours. ${ }^{10)}$ Based on the results of this study, the group without posture dependence showed no significant difference in the 'good compliance group' ratio compared to the position-dependent group, but the average CPAP usage time was significantly longer. There is a result of a previous study that stated that if patients who use CPAP devices change their position during sleep or their oxygen saturation decreased, they usually took off their CPAP devices. ${ }^{13)}$ If a position-dependent OSA patient habitually moves to sleep on their side while sleeping, the average CPAP usage time is likely to be shorter than in the posture-independent group. However, correlation between posture dependence and body movement during sleep is not clear, and there are limitations in the criteria for defining posture dependence.

REM-related OSA patients accounted for $9.4 \%$ of the total, and there was no significant difference in the average 
CPAP usage time and the CPAP compliance rate within 3 months whether or not a patient had REM-related OSA (Table 1). REM-related OSA patients tend to have apnea-hypopnea events focused mainly during REM stage, and REM sleep accounts for about $20 \%$ of total sleep, therefore, it is known that REM-related OSA patients have a lower average $\mathrm{AHI}$ and have more mild-to-moderate patients than the non-REM-related group. ${ }^{14)}$ Therefore, in order to investigate the relationship between the REM-related OSA and CPAP compliance, further studies should be made considering the establishment of an accurate criteria and the relationship between REM-related OSA, gender, and OSA severity.

In comparison of variables between non-telemonitoring and telemonitoring groups, the average $\mathrm{AHI}_{\mathrm{CPAP}}$ was significantly lower in the telemonitoring group than in the nontelemonitoring group (Table 2). However, since the $\mathrm{AHI}_{\mathrm{CPAP}}$ calculation algorithm or the automatic pressure control algorithm may be different depending on the manufacturer of the CPAP device, it cannot be said that the lower $\mathrm{AHI}_{\mathrm{CPAP}}$ group has better control of apnea and has the better CPAP compliance rate. Also, the telemonitoring was one of the affecting factors to compliance of CPAP use (Table 3). Previous study revealed that telemonitored patients used the PAP device in OSA patients with stroke showed longer device usage time significantly, but there was no significant difference in one year later and recommended the telemonitoring every 3 months at least. ${ }^{15)}$ Therefore, we could guess that the telemonitoring could be the factor increasing the compliance rate of PAP therapy and we need regular telemonitoring and to check long term follow up results in our study.

In the fixed CPAP group, the 'good compliance group' ratio was significantly higher than in the APAP group, the average CPAP usage time was longer, and the average $\mathrm{AHI}_{\mathrm{CPAP}}$ was also significantly lower (Table 1 and 2). Although other studies have shown that APAP is as effective in improving apnea, hypopnea, excessive daytime sleepiness, and cognitive impairment as fixed CPAP, the impact on compliance is still controversial. ${ }^{16)}$ In some studies, the group of patients using APAP was found to have a longer average usage time than fixed CPAP. ${ }^{17-19)}$ However, in other studies, APAP had lower mean median pressure compared to fixed CPAP, but there was no significant difference in usage time and compliance. ${ }^{20-22)}$

In our results, there was no significant difference between the CPAP compliance rate and the average usage time ac- cording to the severity of OSA (Table 1 and 2). However, many previous studies on CPAP compliance reported that the severity of OSA correlated to higher CPAP compliance rates. ${ }^{1{ }^{23-26)}}$ In addition, higher patient's age, body mass index, and AHI led to higher CPAP compliance rates. ${ }^{24)}$ It is said that for people with the more severe OSA, greater improvements in respiratory events could be gained through CPAP treatment, and there is a strong motivation to the improve symptoms, so patients would continually use CPAP for a long time. ${ }^{24)}$ Although there was a previous study showing that patients who had high compliance rates within 3 months had high compliance rate with long-term followup results, the possibility of other factors than OSA severity could not be ruled out in the short-term effect on CPAP compliance.

According to this study, the mean age of good compliance group was significantly higher than in poor compliance group at 3-month follow-up, and as the age increased, the probability of good compliance increased (Table 1). Many previous studies of on age and CPAP compliance rate have shown different results. Some studies reported that age and compliance rate showed negative correlation. ${ }^{2728)}$ In another study, the 3-month compliance was reported to be $80.7 \%$ in patients over 60 years old, $92.39 \%$ in the group of patients of age 60 or less. However, age and compliance rate did not correlate. ${ }^{29)}$ Thus, reports of compliance rate related with age had differences depends on the studies. We guess that the Korean national insurance system could be a factor and therer were many young adult who want to try other options of OSA treatment such as surgical treatment or dental device.

This study has several limitations. First, the anatomical factors of OSA patients were not considered. Second, we did not compare the compliance rate before and after starting of coverage the Korean national health insurance system of OSA diagnosis and CPAP therapy. Third, all patients did not use the same manufacture devices. However, we believe that our paper outweighs its limitations due to the fact that, to the best of our knowledge, this is the first trial to investigate the factors influencing to the compliance rate of CPAP therapy in short term follow up in Korea after stating coverage of OSA diagnosis and treatment by the Korean national health insurance system.

When using CPAP at least 4 hours a day and at least 5 times a week is a standard of compliance, according to a previous domestic study, about $40 \%$ of patients are well 
compliant with CPAP between 3 and 6 months. ${ }^{3031)}$ As a result of this study, it was found that $90.5 \%$ of patients were complying with CPAP device based on the degree of compliance similar to that used in previous domestic studies during the insurance compliance period of 3 months. In previous domestic studies before applying insurance coverage for using CPAP, since the only way to do a compliance analysis was to make a phone call, it was difficult to produce systematic and accurate statistics on the CPAP compliance rates. After CPAP's coverage of insurance benefits, data on CPAP usage can now be documented and quantified, allowing more accurate statistics. This study is meaningful in analyzing CPAP compliance and impact on CPAP compliance through documented data after applying CPAP insurance benefits.

In conclusion, at 3-month follow-up of CPAP usage, the ratio of the 'good compliance' group was higher in telemonitoring of CPAP group and fixed CPAP group. In non-position-dependent OSA patients, the average CPAP usage time was longer than those in position-dependent OSA patients. As the age of patients increased, their use of CPAP devices was longer and the tendency to increase compliance rates was shown. If further research is conducted by reinforcing data on long-term users for more than a year and reinforcing the association with the degree of improvement in daytime sleepiness, it is expected that it will contribute to lowering the chances of the Korean government forgoing CPAP insurance benefits and increasing patient satisfaction.

\section{REFERENCES}

1) Kohler M, Smith D, Tippett V, Stradling JR. Predictors of long-term compliance with continuous positive airway pressure. Thorax 2010; 65(9):829-32.

2) Baratta F, Pastori D, Bucci T, Fabiani M, Fabiani V, Brunori M, et al. Long-term prediction of adherence to continuous positive air pressure therapy for the treatment of moderate/severe obstructive sleep apnea syndrome. Sleep Med 2018;43:66-70.

3) Sin DD, Mayers I, Man GC, Pawluk L. Long-term compliance rates to continuous positive airway pressure in obstructive sleep apnea: a population-based study. Chest 2002;121(2):430-5.

4) Nino-Murcia G, McCann CC, Bliwise DL, Guilleminault C, Dement WC. Compliance and side effects in sleep apnea patients treated with nasal continuous positive airway pressure. West J Med 1989;150(2): $165-9$.

5) Wang JF, Fang JR, Xie YP, Ma W, Hui PL, Su XY, et al. [Research on the effects of CPAP for OSA combined CHD long-term prognosis]. Lin Chung Er Bi Yan Hou Tou Jing Wai Ke Za Zhi 2019;33(11): 1031-9.

6) Huang Z, Liu Z, Luo Q, Zhao Q, Zhao Z, Ma X, et al. Long-term effects of continuous positive airway pressure on blood pressure and prognosis in hypertensive patients with coronary heart disease and obstructive sleep apnea: a randomized controlled trial. Am J Hypertens 2015;28(3):300-6.

7) Sarac S, Afsar GC, Oruc O, Topcuoglu OB, Salturk C, Peker Y. Impact of Patient Education on Compliance with Positive Airway Pressure Treatment in Obstructive Sleep Apnea. Med Sci Monit 2017; 23:1792-9.

8) Pelosi LB, Silveira MLC, Eckeli AL, Chayamiti E, Almeida LA, Sander HH, et al. The importance of clinical monitoring for compliance with Continuous Positive Airway Pressure. Braz J Otorhinolaryngol 2017;83(4):439-44.

9) Collen J, Lettieri C, Kelly W, Roop S. Clinical and polysomnographic predictors of short-term continuous positive airway pressure compliance. Chest 2009;135(3):704-9.

10) Iannella G, Magliulo G, Lo Iacono CAM, Bianchi G, Polimeni A, Greco A, et al. Positional Obstructive Sleep Apnea Syndrome in Elderly Patients. Int J Environ Res Public Health 2020;17(3):1120.

11) Kribbs NB, Pack AI, Kline LR, Smith PL, Schwartz AR, Schubert NM, et al. Objective measurement of patterns of nasal CPAP use by patients with obstructive sleep apnea. Am Rev Respir Dis 1993; 147(4):887-95.

12) Woehrle H, Graml A, Weinreich G. Age- and gender-dependent adherence with continuous positive airway pressure therapy. Sleep Med 2011;12(10):1034-6.

13) Yamaguchi Y, Hibi S, Ishii M, Hanaoka Y, Yamamoto H, Ouchi Y, et al. Removal of the CPAP Therapy Device During Sleep and Its Association With Body Position Changes and Oxygen Desaturations. Respir Care 2015;60(5):658-65.

14) Oksenberg A, Arons E, Nasser K, Vander T, Radwan H. REM-related obstructive sleep apnea: the effect of body position. J Clin Sleep Med 2010;6(4):343-8.

15) Kotzian ST, Saletu MT, Schwarzinger A, Haider S, Spatt J, Kranz G, et al. Proactive telemedicine monitoring of sleep apnea treatment improves adherence in people with stroke- a randomized controlled trial (HOPES study). Sleep Med 2019;64:48-55.

16) Hussain SF, Love L, Burt H, Fleetham JA. A randomized trial of auto-titrating CPAP and fixed CPAP in the treatment of obstructive sleep Apnea-Hypopnea. Respir Med 2004;98(4):330-3.

17) Massie CA, McArdle N, Hart RW, Schmidt-Nowara WW, Lankford A, Hudgel DW, et al. Comparison between automatic and fixed positive airway pressure therapy in the home. Am J Respir Crit Care Med 2003;167(1):20-3.

18) Meurice JC, Marc I, Sériès F. Efficacy of auto-CPAP in the treatment of obstructive sleep apnea/hypopnea syndrome. Am J Respir Crit Care Med 1996;153(2):794-8.

19) Hudgel DW, Fung C. A long-term randomized, cross-over comparison of auto-titrating and standard nasal continuous airway pressure. Sleep 2000;23(5):645-8.

20) Teschler H, Wessendorf T, Farhat A, Konietzko N, Berthon-Jones M. Two months auto-adjusting versus conventional nCPAP for obstructive sleep apnoea syndrome. Eur Respir J 2000;15(6):990-5.

21) Randerath WJ, Schraeder O, Galetke W, Feldmeyer F, Ruhle KH. Autoadjusting CPAP therapy based on impedance efficacy, compliance and acceptance. Am J Respir Crit Care Med 2001;163(3 Pt 1): 652-7.

22) d'Ortho MP, Grillier-Lanoir V, Levy P, Goldenberg F, Corriger E, Harf A, et al. Constant vs automatic continuous positive airway pressure therapy: home evaluation. Chest 2000;118(4):1010-7.

23) Mcardle N, Devereux G, Heidarnejad H, Engleman HM, Mackay TW, Douglas NJ. Long-term use of CPAP therapy for sleep apnea/ hypopnea syndrome. Am J Respir Crit Care Med 1999;159(4 Pt 1): 1108-14.

24) Krieger J, Kurtz D, Petiau C, Sforza E, Trautmann D. Long-term 
compliance with CPAP therapy in obstructive sleep apnea patients and in snorers. Sleep 1996;19(9 Suppl):S136-43.

25) Yetkin O, Kunter E, Gunen H. CPAP compliance in patients with obstructive sleep apnea syndrome. Sleep Breath 2008;12(4):365-7.

26) Stepnowsky CJ, Dimsdale JE. Dose-response relationship between CPAP compliance and measures of sleep apnea severity. Sleep Med 2002;3(4):329-34.

27) Janson C, Nöges E, Svedberg-Brandt S, Lindberg E. What characterizes patients who are unable to tolerate continuous positive airway pressure (CPAP) treatment? Respir Med 2000;94(2):145-9.

28) Pieters T, Collard P, Aubert G, Dury M, Delguste P, Rodenstein D. Acceptance and long-term compliance with nCPAP in patients with obstructive sleep apnoea syndrome. Eur Respir J 1996;9(5):939-44.

29) Pelletier-Fleury N, Rakotonanahary D, Fleury B. The age and other factors in the evaluation of compliance with nasal continuous positive airway pressure for obstructive sleep apnea syndrome. A Cox's proportional hazard analysis. Sleep Med 2001;2(3):225-32.

30) Han EK, Yoon IY, Chung S. The compliance and effectof CPAP in obstructive sleep apnea syndrome. Sleep Med and Psychophysiology 2006;13(2):52-28.

31) Kim HY, Jang MS. Improving compliance for continuous positive airway pressure compliance and possible influencing factors. Korean J Otorhinolaryngol-Head NeckSsurg 2014;57:7-14. 